\title{
Additive anti-inflammatory effects of corticosteroids and phosphodiesterase-4 inhibitors in COPD CD8 cells
}

\author{
Seamus Grundy ${ }^{1 *}$, Jonathan Plumb ${ }^{1}$, Manminder Kaur ${ }^{1}$, David Ray ${ }^{2}$ and Dave Singh ${ }^{1}$
}

\begin{abstract}
Background: CD8 lymphocytes play an important role in the pathogenesis of COPD. Corticosteroids and phosphodiesterase 4 (PDE4) inhibitors are anti-inflammatory drugs used for COPD treatment. Little is known of the combined effect of these drugs on COPD CD8 cells. We studied the effect of corticosteroid combined with PDE4 inhibitors on cytokine release form circulating and pulmonary CD8 cells, and on glucocorticoid (GR) nuclear translocation.

Methods: The effect of dexamethasone alone and in combination with the PDE4 inhibitors roflumilast and GSK256066 on cytokine release from circulating and pulmonary CD8 cells was measured. The effect of the compounds on nuclear translocation of GR and cyclic AMP-responsive element-binding protein (CREB) was studied using immunofluorescence.

Results: Dexamethasone inhibited cytokine release from COPD CD8 cells in a concentration dependent manner. PDE4 inhibitors enhanced this anti-inflammatory effect in an additive manner. PDE4 inhibitors did not increase corticosteroid induced GR nuclear translocation. PDE4 inhibitors, but not corticosteroid, increased phospho-CREB nuclear translocation.

Conclusion: The combination of corticosteroids and PDE4 inhibitors results in an additive anti-inflammatory effect in COPD CD8 cells. This enhanced anti-inflammatory effect could translate to important clinical benefits for patients with COPD.
\end{abstract}

Keywords: Chronic Obstructive Pulmonary Disease, CD8, Corticosteroid, Phosphodiesterase 4 inhibitor

\section{Background}

Chronic Obstructive Pulmonary Disease (COPD) is characterised by airflow obstruction and an abnormal inflammatory response to the inhalation of noxious particles, most commonly from cigarette smoking [1]. Lymphocytes play a key role in this inflammatory response; in particular, CD8 cell numbers are increased in the lungs of COPD patients [2-4]. These cells are capable of secreting pro-inflammatory cytokines and cytotoxic molecules such as perforin and granzymes that cause cell death $[5,6]$.

\footnotetext{
* Correspondence: seamus.grundy@aintree.nhs.uk

${ }^{1}$ Centre for Respiratory Medicine and Allergy, Institute of Inflammation and

Repair, Manchester Academic Health Science Centre, The University of

Manchester and University Hospital of South Manchester, NHS Foundation

Trust Southmoor Road, Manchester M23 9LT, UK

Full list of author information is available at the end of the article
}

Inhaled corticosteroids (ICS) are widely used antiinflammatory treatments for COPD. These drugs bind to the cytoplasmic glucocorticoid receptor (GR), forming a complex that translocates to the nucleus, thereby suppressing the activity of transcription factors such as nuclear factor kappa-light-chain-enhancer of activated B cells $(\mathrm{NF}-\mathrm{kB})$ that promote inflammatory gene transcription [7]. ICS are used primarily to prevent exacerbations in COPD patients with a history of exacerbations [8].

Phosphodiesterase 4 (PDE4) inhibitors are the only new class of anti-inflammatory therapy to be licensed for COPD in recent years. PDE4 inhibitors decrease degradation of cyclic adenosine monophosphate (cAMP) in immune cells, leading to a reduction in proinflammatory activity. Roflumilast is the only currently licensed PDE4 inhibitor, and is used to prevent 
exacerbations in severe COPD patients with a history of exacerbations and chronic bronchitis $[9,10]$. This PDE4 inhibitor is an oral treatment that can have systemic side effects such as weight loss and gastro-intestinal disturbance. This had led to efforts to develop inhaled PDE4 inhibitors, such as GSK256066, in order to improve the therapeutic index [11].

Roflumilast and ICS target different cell signalling pathways, and it has been shown combining these drugs in vitro, using healthy human peripheral blood mononuclear cells (PBMCs) and COPD bronchial epithelial cells, results in an additive anti-inflammatory effect $[12,13]$. These in vitro findings are mirrored by the results from the recently published REACT clinical trial, which showed a reduction in exacerbation rates when roflumilast was added to ICS (plus long acting bronchodilator) treatment in COPD patients who were frequent exacerbators [14].

We have further investigated the anti-inflammatory potential of combining corticosteroids and PDE4 inhibitors, by using COPD lymphocytes. We focused on CD8 cells, studying the effects of these drugs alone and in combination on lymphocyte cytokine production. We also evaluated whether PDE4 inhibition enhances GR nuclear translocation.

\section{Methods}

\section{Subjects}

COPD patients, smokers with normal lung function (S) and healthy non-smokers (HNS) were recruited to obtain blood CD8 cells and PBMCs. COPD was diagnosed in accordance with the GOLD strategy document [1]. A separate group of patients who were undergoing lung resection for known or suspected lung cancer were recruited to obtain lung tissue from which to isolate pulmonary CD8 cells. Table 1 shows the patient demographics. The studies performed were approved by the local research ethics committee (South Manchester Research Ethics Committee, reference: 03/SM/396). All subjects gave written informed consent.

\section{Isolation of cells}

PBMCs were isolated by Ficoll-Paque (GE Healthcare, Bucks, UK) density gradient. Circulating CD8 cells were isolated from PBMCs using positive selection CD8 microbeads (Miltenyi Biotec, Bisley, UK) in accordance with manufacturer's instructions.

Pulmonary CD8 cells were isolated as previously described [15]. Briefly, lung tissue was homogenised in a blender. An enriched population of lymphocytes was obtained by Percoll (GE Healthcare) density gradient at percoll concentrations of 40 and $70 \%$. CD8 cells were positively selected from the enriched population of pulmonary lymphocytes using positive selection CD8 microbeads (Miltenyi Biotec).

\section{Cell culture}

PBMCs and peripheral blood CD8 cells were seeded in triplicate in 96 well plates at 100,000 cells per well. Pulmonary CD8 cells were seeded at 50,000 cells per well. Cells were pre-treated for $1 \mathrm{~h}$ with dexamethasone $\left(10^{-6} \mathrm{M}-10^{-10} \mathrm{M}\right)$ alone or in combination with GSK256066 (Stratech, Newmarket, UK, Spain), roflumilast (Sigma-Aldrich, Poole, UK) or forskolin (Sigma-Aldrich). Cells were then stimulated for $24 \mathrm{~h}$ with anti-CD2/3/28 beads (Miltenyi Biotec). Supernatants were harvested and stored at $-20{ }^{\circ} \mathrm{C}$ until ELISA was performed.

\section{Cytokine analysis}

Supernatants were analysed by ELISA according to manufacturer's instructions; IL-2 (R\&D Systems DuoSet, R\&D Systems, Abingdon, UK), IFN (Ready-Set-Go Kit, eBioscience, Herts, UK). Lower limits of detection were $15.6 \mathrm{pg} / \mathrm{ml}$ and $4 \mathrm{pg} / \mathrm{ml}$ for IL-2 and IFN respectively.

Table 1 Subject demographics

\begin{tabular}{|c|c|c|c|c|c|}
\hline & \multicolumn{3}{|c|}{ Peripheral blood CD8 } & \multicolumn{2}{|c|}{ Pulmonary CD8 } \\
\hline & $\operatorname{COPD}(17)$ & $S(10)$ & $\operatorname{HNS}(7)$ & $\operatorname{COPD}(6)$ & $S(4)$ \\
\hline Age (yrs) & $62.6(45-72)$ & $51.9(38-75)$ & $55.8(44-69)$ & $58.7(43-73)$ & $61.3(50-68)$ \\
\hline Male/Female & $14 / 3$ & $3 / 7^{*}$ & $2 / 5^{*}$ & $5 / 1$ & $4 / 0$ \\
\hline $\mathrm{FEV}_{1}(\mathrm{~L})$ & $1.5(0.09)$ & $3.0(0.34)^{*}$ & $3.06(0.35)^{*}$ & $1.75(0.24)$ & $3.11(0.56)^{*}$ \\
\hline FEV1 \% predicted & $53.6(3.5)$ & $96.1(3.83)^{*}$ & $99.6(6.23)^{*}$ & $58.7(9.7)$ & $104.4(11.8)^{*}$ \\
\hline FEV1: FVC (\%)* & $47.2(2.8)$ & $79.1(1.89)^{*}$ & $79.1(2.87)^{*}$ & $58.9(8.4)$ & $76.7(8.9)^{*}$ \\
\hline Current Smoker & 8 & 5 & $0^{*}$ & 3 & 4 \\
\hline Smoking History (pkyr) & $42(5.3)$ & $17.6(4.0)^{*}$ & $0^{*}$ & $42.4(15.5)$ & $36(25.7)$ \\
\hline ICS & 10 & $0^{*}$ & $0^{*}$ & 2 & $0^{*}$ \\
\hline
\end{tabular}

Data presented as mean (SD) or median (range). Data for all experiments are combined in this table. There were no significant differences between demographics of subsets of volunteers for individual experiments. PBMC samples were paired with peripheral blood CD8 cells. Therefore separate demographics for PBMCs not displayed. Statistically significant differences between COPD and other patient groups are indicated by ${ }^{*} p<0.05$. COPD: chronic obstructive pulmonary disease; $\mathrm{S}$ : smoker with normal lung function; HNS: healthy non-smoker; FEV 1 : Forced expiratory volume in $1 \mathrm{~s}$; FVC: forced vital capacity; ICS: inhaled corticosteroids 


\section{Immunofluorescence}

Cytospins were prepared, air dried and fixed in $4 \%$ paraformaldehyde. Cells were labelled for Glucocorticoid receptor alpha (GR, thermoscientific PA1-516) or phospho-CREB (Cell signalling \#9191 s). Nuclei were counterstained with 4 6-diamidino-2-phenylindole (DAPI).

Digital micrographs were obtained using a Nikon Eclipse 80i microscope equipped with a QImaging digital camera and ImagePro Plus 5.1 software (MediaCybernetics,

Marlow, UK). Quantification of the nuclear region was determined using the mean fluorescence intensity (MFI) acquired by ImagePro Plus 5.1 software. Background fluorescence levels were subtracted and nuclear MFI was normalised to basal levels in order to calculate relative changes.

\section{Statistics}

Data was analysed in GraphPad Prism and statistics performed in GraphPad Instat (GraphPad Software, SanDiego, CA, USA; http://www.graphpad.com). Cytokine data were normally distributed. ANOVA was performed to compare drug effects; where ANOVA $p<0.05$, pairwise comparisons were made using Bonferroni multiple comparisons test.

Concentration response curve fitting was performed using least squares nonlinear regression. $\mathrm{EC}_{50}$ and $\mathrm{IC}_{50}$ were calculated using Graphpad Prism from the fitted concentration response curves.

Interaction ratios were calculated from the ratio of observed efficacy $\left(\mathrm{I}_{\mathrm{O}}\right)$ to expected efficacy $\left(\mathrm{I}_{\mathrm{E}}\right)$. The expected efficacy was calculated using the Abbott formula:

$$
\mathrm{I}_{\mathrm{E}}=\mathrm{A}+\mathrm{B}-(\mathrm{AB} / 100)
$$

when A is efficacy of compound A and B is efficacy of compound $\mathrm{B}$.

An interaction ratio between 0.5 and 1.5 is consistent with an additive effect [16].

\section{Results}

\section{Anti-inflammatory effects on blood lymphocytes}

The concentration response effect of GSK256066, roflumilast and forskolin on IL-2 release from PBMCs was studied in order to choose concentrations for further experiments (Additional file 1 and Additional file 2: Figure S1). The following concentrations were selected for further experiments; GSK256066: $10^{-9} \mathrm{M}$; roflumilast: $10^{-7} \mathrm{M}$; forskolin: $10^{-6} \mathrm{M}$. These concentrations were selected as they were below the maximum effect concentration (Emax) but were around the $\mathrm{IC}_{50}$ value thus ensuring pharmacological activity.

PBMCs and circulating CD8 cells were isolated from COPD patients $(n=13), \mathrm{S}(n=8)$ and HNS $(n=7)$. Basal levels of IL-2 and IFN were low for all groups. Anti-
$\mathrm{CD} 2 / 3 / 28$ beads significantly increased the production of both IL-2 and IFN from CD8 cells and PBMCs (Additional file 1: Table S1). There were no significant differences between subject groups in levels of cytokine release from CD8 cells. In PBMCs, levels of stimulated IL-2 release were higher in S (mean $6414.6 \mathrm{pg} / \mathrm{ml}$ ) and HNS (mean $6327.2 \mathrm{pg} / \mathrm{ml}$ ) compared to COPD (mean $2469.3 \mathrm{pg} / \mathrm{ml}), \mathrm{p} \leq 0.05$ for both comparisons.

Dexamethasone inhibited both IL-2 and IFN release from peripheral blood CD8 cells and PBMCs in a concentration dependent manner (Figs. 1 and 2). Inhibition at the highest dexamethasone concentration $\left(10^{-6} \mathrm{M}\right)$ ranged from 61.1 to $68.5 \%$ for IL-2 and from 56.3 to 59.7 \% for IFN in the different subject groups (Emax values are shown in Table 2). The inhibitory effect of dexamethasone was not statistically different between subject groups (ANOVA $p>0.05$ for all concentrations of dexamethasone). Table 2 shows that the $\mathrm{IC}_{50}, \mathrm{EC}_{50}$ and Emax values were numerically similar between groups.

GSK256066 $\left(10^{-9} \mathrm{M}\right)$, roflumilast $\left(10^{-7} \mathrm{M}\right)$ and forskolin $\left(10^{-6} \mathrm{M}\right)$ each caused significant inhibition of both IL-2 and IFN release from stimulated peripheral blood CD8 cells and PBMCs. The inhibitory effects of these compounds was generally $<60 \%$ (Figs. 1 and 2; data points on graphs where $\log [\operatorname{Dex}]=0$ ).

Dexamethasone combined with GSK256066, roflumilast or forskolin resulted in greater inhibition of cytokine release in all subject groups (Figs. 1 and 2, Table 2, Additional file 1: Table S2). This enhanced inhibition was significantly greater than the effect of corticosteroid alone (ANOVA $p<0.05$, Bonferroni $p<0.05$ ) for all conditions except for the dexamethasone $10^{-10} \mathrm{M}$ concentration for both IL-2 and IFN from CD8 cells.

The $\mathrm{EC}_{50}$ and $\mathrm{IC}_{50}$ values were generally lower for dexamethasone combined with GSK256066, roflumilast or forskolin compared to dexamethasone alone in all subject groups (Table 2). Similarly, the Emax values for combination treatments were greater than dexamethasone alone. Calculated interaction ratios were consistent with an additive effect (for example at dexamethasone $10^{-8} \mathrm{M}$ the majority of IR values ranged from 1.0-1.5 for both PBMCs and CD8 cells; see Additional file 1: Table S2).

\section{Anti-inflammatory effects on pulmonary CD8 cells}

Pulmonary CD8 cells were isolated from lung tissue of COPD patients $(n=6)$ and S $(n=4)$. Due to limited cell numbers these experiments were limited to a single PDE4 inhibitor. We selected GSK256066 as it was the most potent in the previous experiments (See Additional file 1: $\mathrm{EC}_{50}$ data). Basal levels of IL-2 and IFN release from pulmonary CD8 cells were low. Anti-CD2/3/28 beads induced a significant increase in release of both 

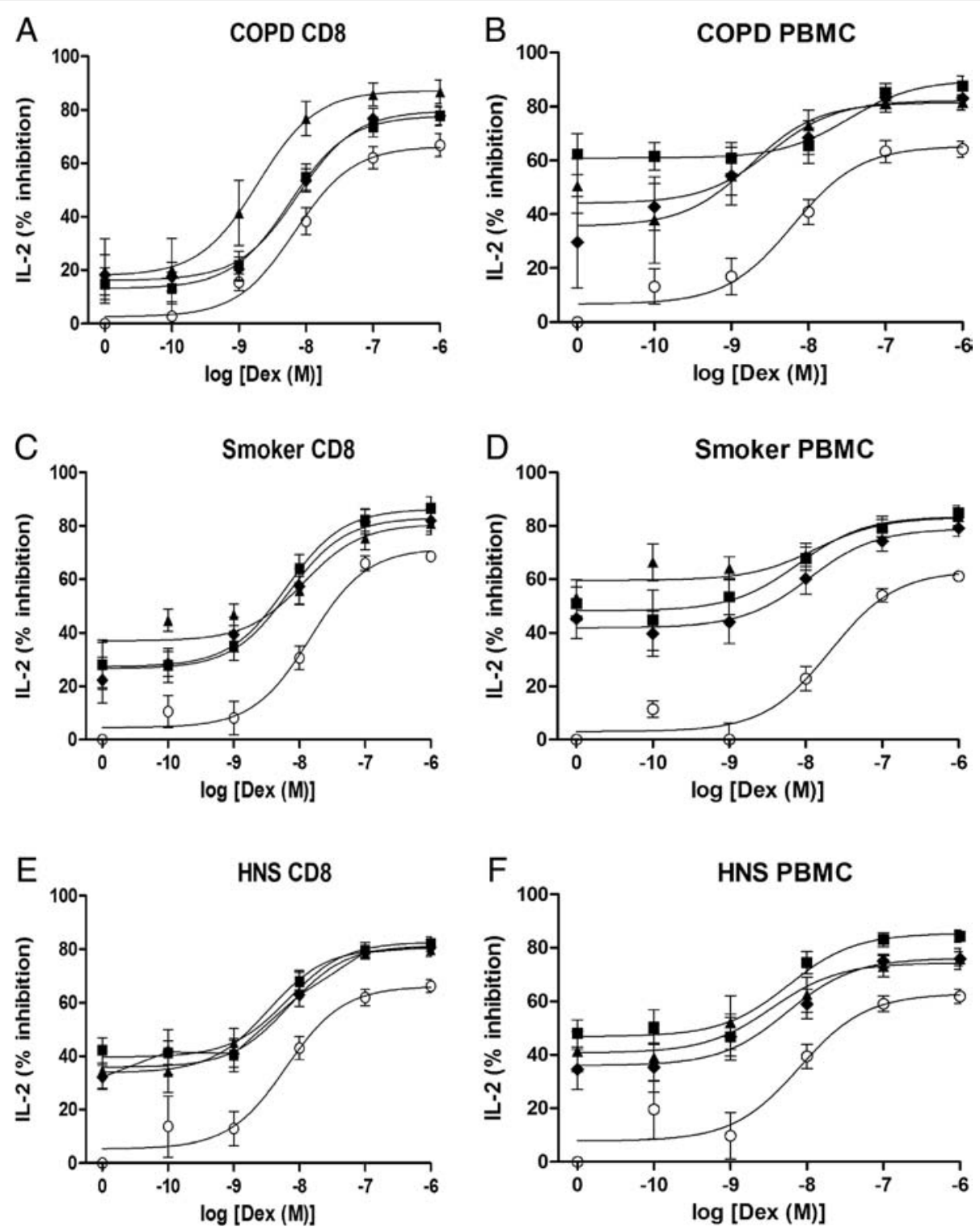

Fig. 1 The effect of PDE4 inhibitors with dexamethasone on IL-2 release from peripheral blood CD8 cells and PBMCs. Peripheral blood CD8 cells and PBMCs from COPD $(n=13, \mathbf{a} \& \mathbf{b})$, Smoker $(n=8, \mathbf{c} \& \mathbf{d})$ and Healthy non-smokers (HNS, $n=7$ e \& $\mathbf{f}$ ) were pre-treated for $1 \mathrm{~h}$ with various

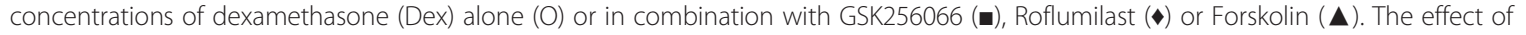
GSK256066, roflumilast and forskolin alone is represented as log[Dex] $=0$. Cells were stimulated for $24 \mathrm{~h}$ with anti-CD2/3/28 beads. Supernatants were harvested and Interleukin 2 (IL-2) was measured by ELISA. Data presented as mean \pm SE

IL-2 and IFN from pulmonary CD8 cells (Additional file 1: Table S1). There were no significant differences between patient groups in levels of cytokine release from pulmonary CD8 cells $(p>0.05$ for both IL-2 and IFN ).

GSK256066 significantly inhibited release of both IL-2 (mean percent inhibition $40.1 \%$ in S, $47.9 \%$ in COPD) and IFN (mean percent inhibition $28.5 \%$ in S, $45.8 \%$ in COPD) from pulmonary CD8 cells with no significant differences between patient groups (Fig. 3). Dexamethasone inhibited cytokine release from pulmonary CD8 cells in a concentration dependent manner with mean inhibition at the highest concentration for IL-2 of 74.1 and $63.5 \%$ for S and COPD respectively and IFN of 68.2 and $48.0 \%$ for $S$ and COPD respectively (Fig. 3). There were no significant differences in effect of dexamethasone between patient groups.

Dexamethasone combined with GSK256066 produced a greater anti-inflammatory effect than dexamethasone alone in both subject groups (Fig. 3). This enhanced anti-inflammatory effect was numerically apparent at most concentrations, but did not always achieve statistical significance. Interaction ratios ranged from 0.9 to 

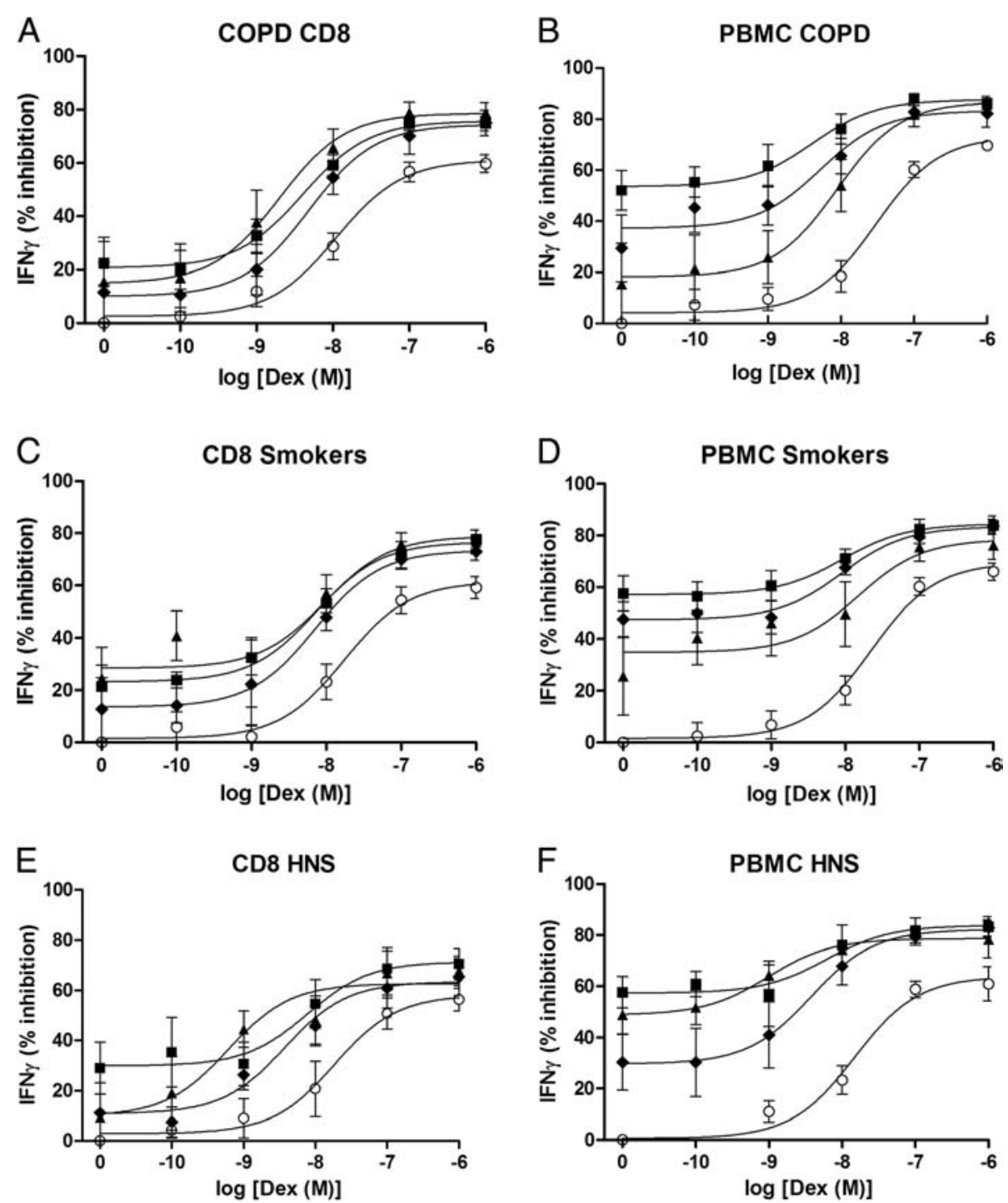

Fig. 2 The effect of PDE4 inhibitors with dexamethasone on IFNY release from peripheral blood CD8 cells and PBMCs. Peripheral blood CD8 cells and PBMCs from COPD $(n=13, \mathbf{a} \& \mathbf{b})$, Smoker $(n=8 \mathbf{c} \& \mathbf{d})$ and Healthy non-smokers (HNS, $n=7, \mathbf{e} \& \mathbf{f})$ were pre-treated for $1 \mathrm{~h}$ with various concentrations of dexamethasone (Dex) alone (O) or in combination with GSK256066 ( $\mathbf{\bullet})$, Roflumilast ( ) or Forskolin ( $\mathbf{\Delta})$. The effect of GSK256066, roflumilast and forskolin alone is represented as $\log [\mathrm{Dex}] \mathrm{M}=0$. Cells were stimulated for $24 \mathrm{~h}$ with anti-CD2/3/28 beads. Supernatants were harvested and Interferon gamma (IFNY) was measured by ELISA. Data presented as mean \pm SE

1.4 for all studied concentrations of dexamethasone (Table 3). This is consistent with an additive effect for dexamethasone and GSK256066 combined.

\section{GR nuclear translocation}

In resting blood CD8 cells from COPD patients $(n=5)$, GR was predominantly visualised within the cytoplasm. Treatment with dexamethasone resulted in nuclear translocation of GR. Treatment with GSK256066 and forskolin alone also produced nuclear translocation of GR. Roflumilast alone had no effect on the sub-cellular location of GR. The combination of dexamethasone with
GSK256066, roflumilast or forskolin did not result in any greater level of nuclear GR compared to dexamethasone alone (Fig. 4).

\section{CREB nuclear translocation}

In unstimulated peripheral blood CD8 cells, dexamethasone had no significant effect on nuclear translocation of p-CREB. In contrast, GSK256066 and forskolin increased nuclear p-CREB localisation. The addition of dexamethasone to GSK256066 or forskolin had no additional effect on p-CREB nuclear translocation compared to GSK256066 alone (Fig. 5). 
Table 2 Mean $\mathrm{EC}_{50}, \mathrm{IC}_{50}$ and $\mathrm{E}_{\max }$ for dexamethasone alone and in combination with PDE4 inhibitors in blood CD8 cells and PBMCs

\begin{tabular}{|c|c|c|c|c|c|}
\hline & & Dex & Dex/256066 & Dex/Rof & Dex/Forsk \\
\hline & & \multicolumn{4}{|c|}{ Mean $\mathrm{EC}_{50} \mathrm{IL}-2$} \\
\hline \multirow[t]{3}{*}{ CD8 } & COPD & 7.8 & 4.8 & 6.7 & 1.6 \\
\hline & Smoker & 16.6 & 5.4 & 6.1 & 14.1 \\
\hline & HNS & 11.2 & 5.4 & 7.7 & 2.7 \\
\hline \multirow[t]{4}{*}{ PBMC } & COPD & 8.91 & 11.4 & 4.2 & 2.2 \\
\hline & Smoker & 22.9 & 8.3 & 8.7 & 18.2 \\
\hline & HNS & 12.0 & 4.9 & 3.8 & 2.0 \\
\hline & & \multicolumn{4}{|c|}{ Mean $\mathrm{EC}_{50} \mathrm{IFNy}$} \\
\hline \multirow[t]{3}{*}{ CD8 } & COPD & 10.0 & 4.0 & 5.0 & 1.6 \\
\hline & Smoker & 20.0 & 6.3 & 7.9 & 10.0 \\
\hline & HNS & 15.8 & 12.6 & 3.2 & 5.0 \\
\hline \multirow[t]{4}{*}{ PBMC } & COPD & 31.6 & 4.0 & 6.3 & 10.0 \\
\hline & Smoker & 20.0 & 10.0 & 7.9 & 15.8 \\
\hline & HNS & 10.0 & 4.0 & 2.5 & 2.5 \\
\hline & & \multicolumn{4}{|c|}{ Mean $I_{50} I L-2$} \\
\hline \multirow[t]{3}{*}{ CD8 } & COPD & 7.9 & 5.5 & 7.1 & 1.8 \\
\hline & Smoker & 16.6 & 6.2 & 8.5 & 22.9 \\
\hline & HNS & 7.9 & 5.9 & 8.3 & 3.2 \\
\hline \multirow[t]{4}{*}{ PBMC } & COPD & 8.5 & 30.2 & 4.8 & 1.6 \\
\hline & Smoker & 22.9 & 6.6 & 9.3 & 33.9 \\
\hline & HNS & 10.7 & 5.5 & 6.5 & 3.1 \\
\hline & & \multicolumn{4}{|c|}{ Mean $\mathrm{IC}_{50} \mathrm{IFNy}$} \\
\hline \multirow[t]{3}{*}{ CD8 } & COPD & 12.0 & 3.6 & 4.6 & 1.9 \\
\hline & Smoker & 18.2 & 8.1 & 7.4 & 11.0 \\
\hline & HNS & 21.4 & 8.1 & 3.6 & 0.8 \\
\hline \multirow[t]{4}{*}{ PBMC } & COPD & 33.1 & 5.0 & 8.5 & 9.8 \\
\hline & Smoker & 23.4 & 8.7 & 8.9 & 24.0 \\
\hline & HNS & 15.1 & 6.0 & 3.6 & 1.0 \\
\hline & & \multicolumn{4}{|c|}{$E_{\max } \| L 2$} \\
\hline \multirow[t]{3}{*}{ CD8 } & COPD & 67.9 & 78.1 & 78.2 & 86.6 \\
\hline & Smoker & 68.5 & 86.5 & 81.9 & 80.9 \\
\hline & HNS & 66.3 & 82.0 & 80.7 & 79.7 \\
\hline \multirow[t]{4}{*}{ PBMC } & COPD & 64.2 & 87.4 & 83.0 & 81.6 \\
\hline & Smoker & 61.1 & 84.8 & 79.2 & 84.1 \\
\hline & HNS & 61.9 & 84.3 & 75.9 & 77.5 \\
\hline & & \multicolumn{4}{|c|}{$E_{\max } I F N y$} \\
\hline \multirow[t]{3}{*}{ CD8 } & COPD & 59.8 & 74.9 & 75.1 & 78.8 \\
\hline & Smoker & 59.2 & 77.6 & 72.9 & 76.6 \\
\hline & HNS & 56.3 & 70.5 & 65.4 & 75.4 \\
\hline
\end{tabular}

Table 2 Mean $\mathrm{EC}_{50}, \mathrm{IC} \mathrm{C}_{50}$ and $\mathrm{E}_{\max }$ for dexamethasone alone and in combination with PDE4 inhibitors in blood CD8 cells and PBMCs (Continued)

\begin{tabular}{llllll}
\hline PBMC & COPD & 69.7 & 86.4 & 82.2 & 85.7 \\
& Smoker & 66.0 & 84.0 & 83.6 & 75.4 \\
& HNS & 61.0 & 83.2 & 82.9 & 73.7 \\
\hline
\end{tabular}

Data presented mean nanomolar concentration for $\mathrm{EC}_{50}$ and $\mathrm{IC}_{50}$. Data presented as mean percent inhibition for $E_{\max }$. Dex: dexamethasone; 256066 : GSK256066;CD8: circulating CD8 cells; PBMC: peripheral blood mononuclear cells; Rof: roflumilast; Forsk: forskolin; COPD: chronic obstructive pulmonary disease; HNS: healthy non-smoker; IL-2: interleukin 2; IFNY: interferon gamma; $\mathrm{EC}_{50}$ :concentration producing $50 \%$ of maximal effect; $\mathrm{IC}_{50}$ : concentration producing reduction of $50 \%$ relative to untreated stimulated levels; $E_{\max }$ : Maximal inhibitory effect at dexamethasone $10^{-6} \mathrm{M}$

\section{Discussion}

The combination of dexamethasone with PDE4 inhibitors had an additive anti-inflammatory effect on both circulating and pulmonary CD8 cells from COPD patients and controls. These drug classes can be used in combination in clinical practice [14]; we show that this clinical strategy causes additive anti-inflammatory effects on a cell type involved in COPD inflammation. This additive anti-inflammatory effect is due to PDE4 inhibitors influencing cAMP signalling, which is not affected by corticosteroids.

We used sub-maximal concentrations of the PDE4 inhibitors roflumilast and GSK256066 to evaluate interactions with corticosteroid. In PBMCs, which contain both CD4 and CD8 cells, and isolated CD8 cells, we observed the same phenomenon; PDE4 inhibition provided an additional anti-inflammatory effect on top of that caused by dexamethasone. This resulted in a greater Emax (maximal inhibitory effect) and a reduced $\mathrm{EC}_{50}$ value for combination treatment. It is interesting that this additive effect was present at the majority of corticosteroid concentrations, as it implies that this effect may also be observed in clinical practice across a range of drug concentrations. The use of forskolin, which is known to increase cAMP levels, in these experiments provided confirmation that the additive effect was due to the combination of cAMP modulation with GR activation. Previous work has suggested that cAMP signalling may oppose glucocorticoid action [17, 18]. However, we show that this does not occur in COPD lymphocytes, as an additive effect is observed with simultaneous cAMP modulation with GR activation.

The number of experiments possible with lung cells was reduced due to the lower number of cells available. We chose to only use GSK256066 for these experiments, as it had been the most potent in our hands, which is consistent with previous publications comparing this drug to roflumilast [19]. The results from lung CD8 cells showed the same pattern as blood, but the experimental variability was greater and so statistical significance was 


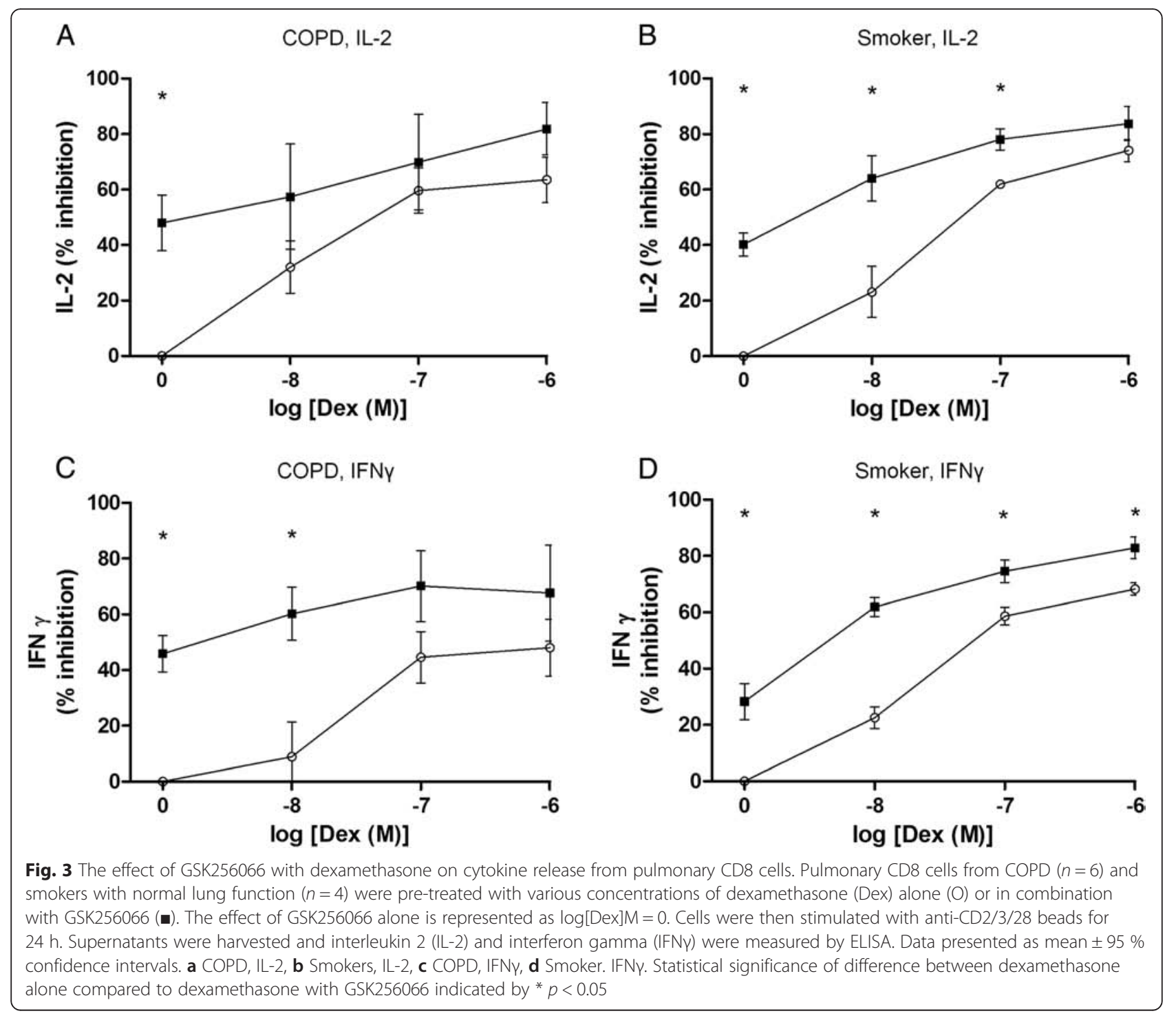

Table 3 Interaction ratios for combination of dexamethasone and GSK256066 on pulmonary CD8 cells

\begin{tabular}{lllllll}
\hline & COPD & \multicolumn{5}{c}{ Smokers } \\
\hline & \multicolumn{5}{c}{ Interaction ratio IL-2 } \\
Dex (M) & $10^{-8}$ & $10^{-7}$ & $10^{-6}$ & $10^{-8}$ & $10^{-7}$ & $10^{-6}$ \\
$\mathrm{I}_{0}$ & 57.3 & 69.9 & 81.1 & 64.0 & 78.1 & 83.8 \\
$\mathrm{I}_{\mathrm{E}}$ & 64.5 & 79.0 & 81.0 & 54.1 & 77.2 & 84.6 \\
IR & 0.9 & 0.9 & 1.0 & 1.2 & 1.1 & 1.0 \\
& \multicolumn{5}{c}{ Interaction ratio IFNY } \\
\end{tabular}

\begin{tabular}{lllllll} 
Dex (M) & $10^{-8}$ & $10^{-7}$ & $10^{-6}$ & $10^{-8}$ & $10^{-7}$ & $10^{-6}$ \\
$\mathrm{I}_{\mathrm{O}}$ & 60.2 & 70.1 & 67.6 & 61.9 & 74.6 & 82.9 \\
$\mathrm{I}_{\mathrm{E}}$ & 50.7 & 70 & 71.9 & 44.4 & 70.4 & 77.2 \\
$\mathrm{IR}$ & 1.2 & 1.0 & 0.9 & 1.4 & 1.1 & 1.1 \\
\hline
\end{tabular}

Data presented as percent inhibition relative to cells stimulated with anti-CD2/3/28 $\mathrm{l}_{\mathrm{O}} \& \mathrm{l}_{\mathrm{E}}$. $I R$ is the ratio of $\mathrm{I}_{0}$ to $\mathrm{I}_{E}$ COPD: chronic obstructive pulmonary disease; Dex: dexamethasone; IL-2: interleukin 2; IFNץ. interferon gamma; lo: Observed inhibition; lE: Expected inhibition; IR: interaction ratio. An interaction ratio between 0.5 and 15 is consistent with additive effect not reached for every concentration when analysing whether two drugs had a greater effect than one. Nevertheless, our results overall show the potential for additive anti-inflammatory effects on COPD CD8 cells when PDE4 inhibitors and corticosteroids are used together.

The calculation of the IR indicated additive, and not synergistic, effects on cytokine production. Furthermore, we saw no enhancement of ligand dependent GR nuclear translocation by PDE4 inhibition. Previous studies in lung cell lines, such as epithelium and airway smooth muscle, have shown a synergistic effect when corticosteroids are combined with compounds that increase intracellular cAMP levels [20-22]. We did not observe synergy in lymphocytes, indicating that synergy between PDE4 inhibitors and corticosteroids does not occur in all cell types. Similarly, Toll-like receptor 3 stimulation of COPD bronchial epithelial cells resulted in cytokine production that was suppressed by PDE4 inhibition and 


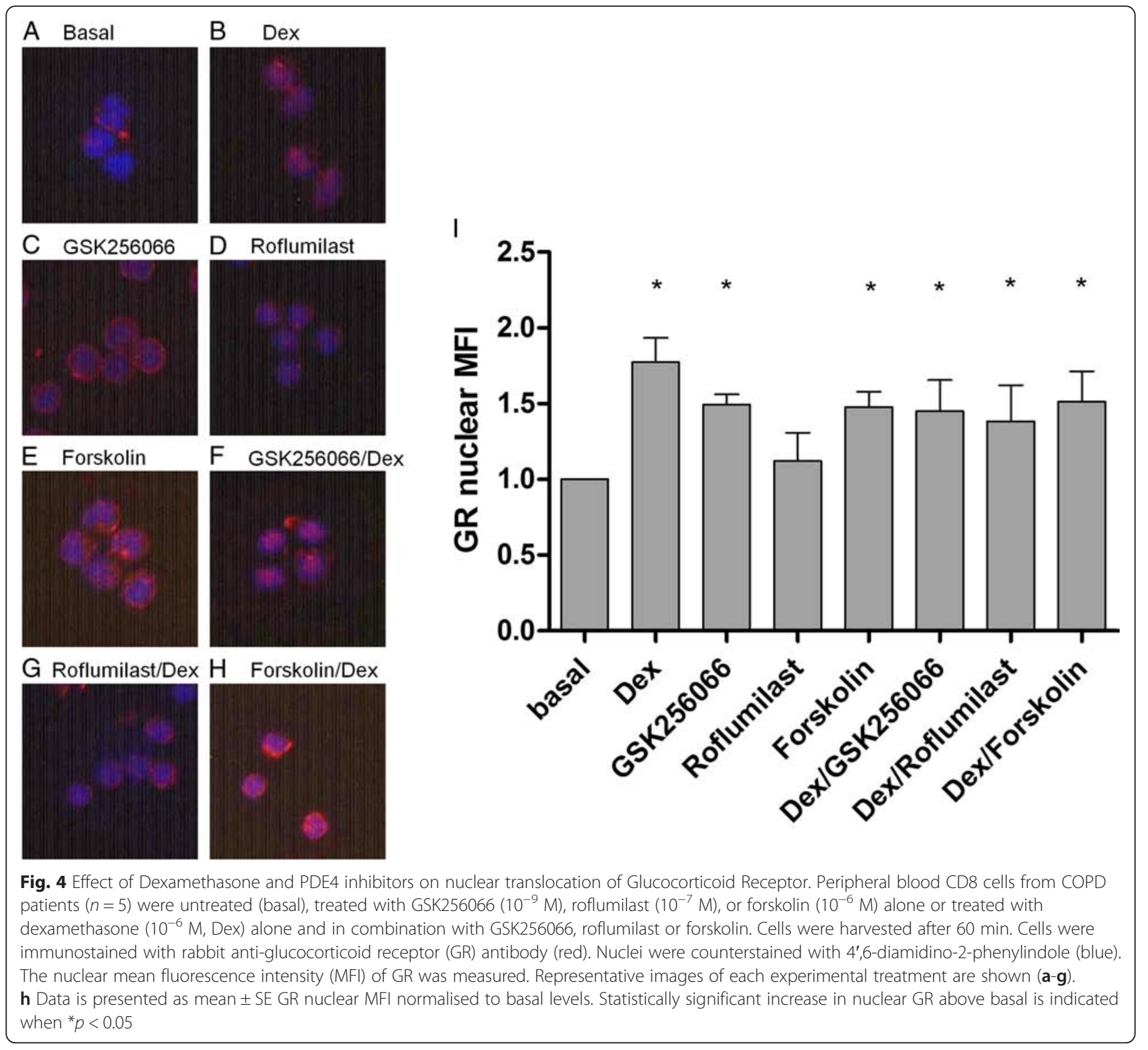

corticosteroid in an additive, and not synergistic, manner [12]. This further supports the concept that additive or synergistic interactions between these drugs classes vary according to the cell type used, and whether these are cell lines or freshly obtained primary cells from COPD patients.

Ligand-independent nuclear translocation of GR is known to occur in response to 2 -adrenoreceptor agonists [23]. Similar to PDE4 inhibitors, 2 -adrenoreceptor agonists also increase intracellular cAMP levels. We also observed some evidence that PDE4 inhibition and forskolin (without corticosteroid) enhance GR nuclear translocation. Thus, it seems likely that cAMP has a direct effect on GR nuclear translocation in lymphocytes. However, GR nuclear translocation caused by cAMP may not result in enhanced GR anti-inflammatory activity, and it would be necessary to study DNA binding of GR in response to PDE4 inhibitors to understand this. Furthermore, there was no additive GR nuclear translocation when PDE4 inhibitors were used with corticosteroids in lymphocytes, indicating that this is not a mechanism that causes additive anti-inflammatory effects.

PDE4 inhibitors, but not corticosteroid, increased nuclear p-CREB; this transcription factor is known to be cAMP responsive. This observation provides evidence that PDE4 inhibition modulates cell signalling pathways that are unaffected by corticosteroids. cAMP is known to regulate production of cytokines such as IL-2 [24, 25], while corticosteroids suppress pro-inflammatory cytokine transcription through transrepression mechanisms such as interference with NF-kB activity [7]. The targeting of different signalling pathways offers the likely 


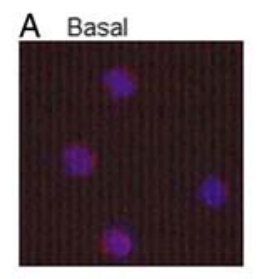

\section{B ous}

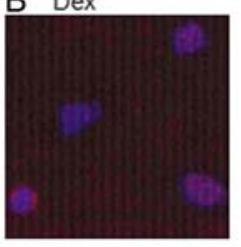

C GSK256066

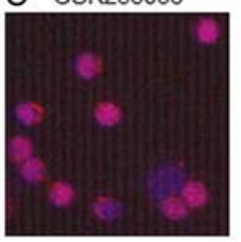

E Dex/GSK256066

\section{Forskolin}

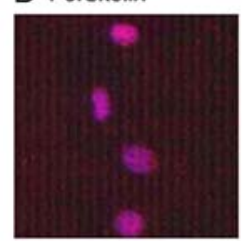

F Dex/Forskolin

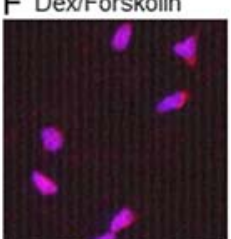

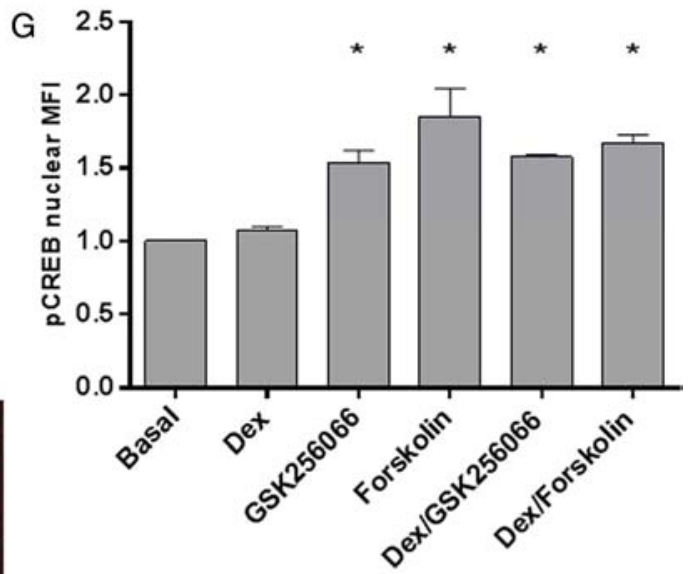

Fig. 5 The effect of dexamethasone and PDE4 inhibitors of nuclear translocation of phoshporylated-CREB. Peripheral blood CD8 cells were isolated from 4 COPD patients. Cells were treated with GSK256066 $\left(10^{-9} \mathrm{M}\right)$ or forskolin $\left(10^{-6} \mathrm{M}\right)$ alone or dexamethasone $\left(10^{-6} \mathrm{M}\right)$ alone and in combination with GSK256066 or forskolin. Cells were immunostained with rabbit anti-phospho-CAMP response element binding (pCREB, red). Nuclei were counterstained with 4',6-diamidino-2-phenylindole (blue). The nuclear mean fluorescence intensity (MFI) of pCREB was measured. Representative images of each experimental condition $(\mathbf{a}-\mathbf{g})$. Data is presented as mean \pm SE pCREB nuclear MFI (H). Statistically significant increase in nuclear $\mathrm{PCREB}$ is indicated when ${ }^{*} p<0.05$

explanation for additive effects reported here when these drug classes are combined. Beta agonists modulate cAMP signalling, and there is evidence that roflumilast interacts with beta-agonists in epithelial cells to enhance corticosteroid effects. This is worthy of study in COPD lymphocytes.

The anti-inflammatory effects of dexamethasone were similar in COPD patients and controls, both in PBMCs and CD8 cells from the blood and lung tissue. We have previously reported similar corticosteroid sensitivity in COPD and control CD8 cells from blood and lung tissue [15]. In contrast, stimulated bronchoalveolar lavage lymphocytes, containing CD4 and CD8 cells, show decreased corticosteroid sensitivity in COPD patients compared to controls [26]. This highlights the potential of corticosteroid effects on COPD lymphocytes to differ according to the anatomical location of the cells, and possibly the ratio of CD4 and CD8 cells present.

CD8 cells are capable of playing a variety of proinflammatory roles in COPD, such as the secretion of pro-inflammatory cytokines and cytotoxic molecules including perforin and granzymes $[5,6]$. These cells are commonly involved in the host response to pathogens such as viruses and bacteria. COPD exacerbations are often caused by viruses and bacteria, and are characterised by an excessive pro-inflammatory response to the pathogen [27]. The role of cytotoxic CD8 cells in the response to virus infection is well known [28], and these cells also produce a pro-inflammatory response to bacteria; this has been demonstrated using COPD lung CD8 cells [29]. Inhaled corticosteroids are used to prevent the excessive immune response that occurs during exacerbations. The pharmacological interaction demonstrated in this paper may be useful for limiting any role that CD8 cells play in the inflammatory cascade during COPD exacerbations.

We used T-cell receptor stimulation to evaluate the effects of drugs on CD8 cytokine production. CD8 cells express TLR receptors [30], and it would be interesting to investigate the effects of corticosteroids and PDE4 
inhibitors on TLR stimulated CD8 cells. This could include a wider range of cytokines than those studied here, such as IL-17, IL-13 and IL-10.

Stimulated IL-2 levels from PBMCs were lower in COPD patients compared to controls. This pattern was not observed for IFN secretion from PBMCs, nor were there any differences between COPD patients and controls for cytokine release from blood or lung CD8 cells. The lower IL-2 levels from COPD PBMCs may be a false positive finding in a relatively limited sample size, as there was no other evidence for reduced cytokine production in our other experiments. Other papers investigating lymphocyte cytokine secretion from PBMCs have produced varying results, with more evidence for increased secretion from COPD cells [31-34].

\section{Conclusions}

Clinical data shows that roflumilast causes additional clinical benefits when added to ICS in COPD patients $[14,35]$. Our COPD lymphocyte data indicates that the combination of these drugs causes an additive antiinflammatory effect on lymphocyte cytokine production. Given the important role of lymphocytes in the pathophysiology of COPD, our results could represent one mechanism by which the clinical benefit of combining these drug classes occurs. Furthermore, our data support combining these drug classes in order to increase the magnitude of anti-inflammatory effect on COPD lung cells.

\section{Additional files}

Additional file 1: Supplementary data and Tables S1 \& S2. (DOCX $20 \mathrm{~kb}$ )

Additional file 2: Figure S1. Effect of GSK256066, Roflumilast and Forskolin on release of IL-2 in peripheral blood CD8 cells. Peripheral blood CD8 cells from healthy non-smokers $(n=2)$ were pre-treated with stated concentrations of GSK256066 (A), Roflumilast (B) or Forskolin (C) for $1 \mathrm{~h}$ prior to stimulation with anti-CD2/3/28 beads for $24 \mathrm{~h}$. Supernatants were harvested and interleukin 2 (IL-2) was measured by ELISA. Data presented as mean \pm SE \% inhibition of IL-2. (PNG $43 \mathrm{~kb}$ )

\section{Competing interests}

SG has received lecture fees and support for conference attendance from pharmaceutical companies including GSK, Novartis, Boehringer Ingelheim and AstraZeneca.

DS has received lectures fees, support for conference attendance, advisory board fees, and research grants from a range of pharmaceutical companies, including GlaxoSmithKline, Chiesi Pharmaceuticals, AstraZeneca, CIPLA, Novartis, Forest, MSD, Boehringer Ingelheim, and Allmiral.

JP,MK \& DR have no competing interests to declare.

\section{Authors' contributions}

Participated in research design: SG, JP, MK, DR, DS. Conducted experiments: SG, JP, MK. Performed data analysis: SG, JP, MK, DR, DS. Wrote or contributed to writing of manuscript: SG, JP, MK, DR, DS. All authors read and approved the final manuscript.

\section{Acknowledgments}

This work was supported by the Wellcome Trust [Grant number WT092281MA]
This report is independent research supported by National Institute for Health Research Respiratory and Allergy Clinical Research Facility at University Hospital of South Manchester NHS Foundation Trust. The views expressed in this publication are those of the author(s) and not necessarily those of the NHS, the National Institute for Health Research or the Department of Health.

\section{Author details}

${ }^{1}$ Centre for Respiratory Medicine and Allergy, Institute of Inflammation and Repair, Manchester Academic Health Science Centre, The University of Manchester and University Hospital of South Manchester, NHS Foundation Trust Southmoor Road, Manchester M23 9LT, UK. ${ }^{2}$ School of Medicine and Manchester Academic Health Science Centre, University of Manchester, Oxford Road, Manchester M13 9PT, UK.

Received: 27 August 2015 Accepted: 13 January 2016 (t)

\section{References}

1. Vestbo J, Hurd SS, Agusti AG, Jones PW, Vogelmeier C, Anzueto A, et al. Global strategy for the diagnosis, management, and prevention of chronic obstructive pulmonary disease: GOLD executive summary. Am J Respir Crit Care Med. 2013;187(4):347-65.

2. Saetta M, Di Stefano A, Turato G, Facchini FM, Corbino L, Mapp CE, et al. CD8+ T-lymphocytes in peripheral airways of smokers with chronic obstructive pulmonary disease. Am J Respir Crit Care Med. 1998;157(3 Pt 1):822-6.

3. Hogg JC, Chu F, Utokaparch S, Woods R, Elliott WM, Buzatu L, et al. The nature of small-airway obstruction in chronic obstructive pulmonary disease. N Engl J Med. 2004;350(26):2645-53.

4. O'Shaughnessy TC, Ansari TW, Barnes NC, Jeffery PK. Inflammation in bronchial biopsies of subjects with chronic bronchitis: inverse relationship of CD8+ T lymphocytes with FEV1. Am J Respir Crit Care Med. 1997;155(3):852-7.

5. Chrysofakis G, Tzanakis N, Kyriakoy D, Tsoumakidou M, Tsiligianni I, Klimathianaki M, et al. Perforin expression and cytotoxic activity of sputum CD8+ lymphocytes in patients with COPD. Chest. 2004;125(1):71-6.

6. Majo J, Ghezzo H, Cosio MG. Lymphocyte population and apoptosis in the lungs of smokers and their relation to emphysema. Eur Respir J. 2001;17(5):946-53.

7. Barnes PJ. Anti-inflammatory actions of glucocorticoids: molecular mechanisms. Clin Sci (Lond). 1998;94(6):557-72.

8. Alsaeedi A, Sin DD, McAlister FA. The effects of inhaled corticosteroids in chronic obstructive pulmonary disease: a systematic review of randomized placebo-controlled trials. Am J Med. 2002;113(1):59-65.

9. Calverley PM, Rabe KF, Goehring UM, Kristiansen S, Fabbri LM, Martinez FJ. Roflumilast in symptomatic chronic obstructive pulmonary disease: two randomised clinical trials. Lancet. 2009:374(9691):685-94.

10. Fabbri LM, Calverley PM, Izquierdo-Alonso JL, Bundschuh DS, Brose M, Martinez FJ, et al. Roflumilast in moderate-to-severe chronic obstructive pulmonary disease treated with longacting bronchodilators: two randomised clinical trials. Lancet. 2009:374(9691):695-703.

11. Singh D, Petavy F, Macdonald AJ, Lazaar AL, O'Connor BJ. The inhaled phosphodiesterase 4 inhibitor GSK256066 reduces allergen challenge responses in asthma. Respir Res. 2010;11:26.

12. Milara J, Morell A, Ballester B, Sanz C, Freire J, Qian X, et al. Roflumilast improves corticosteroid resistance COPD bronchial epithelial cells stimulated with toll like receptor 3 agonist. Respir Res. 2015;16(1):12.

13. Tannheimer SL, Sorensen EA, Haran AC, Mansfield CN, Wright CD, Salmon M. Additive anti-inflammatory effects of beta 2 adrenoceptor agonists or glucocorticosteroid with roflumilast in human peripheral blood mononuclear cells. Pulm Pharmacol Ther. 2012;25(2):178-84.

14. Martinez FJ, Calverley PM, Goehring UM, Brose M, Fabbri LM, Rabe KF. Effect of roflumilast on exacerbations in patients with severe chronic obstructive pulmonary disease uncontrolled by combination therapy (REACT): a multicentre randomised controlled trial. Lancet. 2015;385(9971):857-66.

15. Grundy S, Kaur M, Plumb J, Reynolds S, Hall S, House D, et al. CRAC channel inhibition produces greater anti-inflammatory effects than glucocorticoids in CD8 cells from COPD patients. Clin Sci (Lond). 2013;126(3):223-32. 
16. Gisi U. Synergistic interaction of fungicides in mixtures. Phytopathology. 1996;86(11):1273-9.

17. Doucas V, Shi Y, Miyamoto S, West A, Verma I, Evans RM. Cytoplasmic catalytic subunit of protein kinase A mediates cross-repression by NF-kappa B and the glucocorticoid receptor. Proc Natl Acad Sci U S A. 2000;97(22):11893-8.

18. Rangarajan PN, Umesono K, Evans RM. Modulation of glucocorticoid function by protein kinase A. Mol Endocrinol. 1992;6(9):1451-7.

19. Nials AT, Tralau-Stewart CJ, Gascoigne MH, Ball DI, Ranshaw LE, Knowles RG. In vivo characterization of GSK256066, a high-affinity inhaled phosphodiesterase 4 inhibitor. J Pharmacol Exp Ther. 2011;337(1):137-44.

20. Kaur M, Chivers JE, Giembycz MA, Newton R. Long-acting beta2adrenoceptor agonists synergistically enhance glucocorticoid-dependent transcription in human airway epithelial and smooth muscle cells. Mol Pharmacol. 2008:73(1):203-14.

21. Wilson SM, Shen P, Rider CF, Traves SL, Proud D, Newton R, et al. Selective prostacyclin receptor agonism augments glucocorticoid-induced gene expression in human bronchial epithelial cells. J Immunol. 2009;183(10):6788-99.

22. Moodley T, Wilson S, Joshi T, Rider C, Sharma P, Yan D, et al. Phosphodiesterase 4 Inhibitors Augment the Ability of Formoterol to Enhance Glucocorticoid-Dependent Gene Transcription in Human Airway Epithelial Cells: A Novel Mechanism for the Clinical Efficacy of Roflumilast in Severe COPD. Mol Pharmacol. 2013;83(4):894-906.

23. Eickelberg $\mathrm{O}$, Roth $\mathrm{M}$, Lorx R, Bruce V, Rudiger J, Johnson M, et al. Ligand-independent activation of the glucocorticoid receptor by beta2-adrenergic receptor agonists in primary human lung fibroblasts and vascular smooth muscle cells. J Biol Chem. 1999;274(2):1005-10.

24. Chen D, Rothenberg EV. Interleukin 2 transcription factors as molecular targets of CAMP inhibition: delayed inhibition kinetics and combinatorial transcription roles. J Exp Med. 1994;179(3):931-42.

25. Mary D, Aussel C, Ferrua B, Fehlmann M. Regulation of interleukin 2 synthesis by CAMP in human T cells. J Immunol. 1987;139(4):1179-84.

26. Kaur M, Smyth LJ, Cadden P, Grundy S, Ray D, Plumb J, et al. T lymphocyte insensitivity to corticosteroids in chronic obstructive pulmonary disease. Respir Res. 2012;13:20.

27. Bafadhel M, McKenna S, Terry S, Mistry V, Reid C, Haldar P, et al. Acute exacerbations of chronic obstructive pulmonary disease: identification of biologic clusters and their biomarkers. Am J Respir Crit Care Med. 2011; 184(6):662-71.

28. Rossey I, Sedeyn K, De Baets S, Schepens B, Saelens X. CD8+ T cell immunity against human respiratory syncytial virus. Vaccine. 2014;32(46):6130-7.

29. King PT, Lim S, Pick A, Ngui J, Prodanovic Z, Downey W, et al. Lung T-cell responses to nontypeable Haemophilus influenzae in patients with chronic obstructive pulmonary disease. J Allergy Clin Immunol. 2013;131(5):1314-21.

30. Freeman CM, Martinez FJ, Han MK, Washko Jr GR, McCubbrey AL, Chensue SW, et al. Lung CD8+ T cells in COPD have increased expression of bacterial TLRs. Respir Res. 2013;14(1):13.

31. Hodge G, Nairn J, Holmes M, Reynolds PN, Hodge S. Increased intracellular Thelper 1 proinflammatory cytokine production in peripheral blood, bronchoalveolar lavage and intraepithelial T cells of COPD subjects. Clin Exp Immunol. 2007;150(1):22-9.

32. Majori M, Corradi M, Caminati A, Cacciani G, Bertacco S, Pesci A. Predominant TH1 cytokine pattern in peripheral blood from subjects with chronic obstructive pulmonary disease. J Allergy Clin Immunol. 1999;103(3 Pt 1):458-62.

33. Barczyk A, Pierzchala W, Kon OM, Cosio B, Adcock IM, Barnes PJ. Cytokine production by bronchoalveolar lavage $T$ lymphocytes in chronic obstructive pulmonary disease. J Allergy Clin Immunol. 2006;117(6):1484-92.

34. Barcelo B, Pons J, Fuster A, Sauleda J, Noguera A, Ferrer JM, et al. Intracellular cytokine profile of T lymphocytes in patients with chronic obstructive pulmonary disease. Clin Exp Immunol. 2006;145(3):474-9.

35. Rennard SI, Calverley PM, Goehring UM, Bredenbroker D, Martinez FJ. Reduction of exacerbations by the PDE4 inhibitor roflumilast-the importance of defining different subsets of patients with COPD. Respir Res. 2011;12:18.

\section{Submit your next manuscript to BioMed Central and we will help you at every step:}

- We accept pre-submission inquiries

- Our selector tool helps you to find the most relevant journal

- We provide round the clock customer support

- Convenient online submission

- Thorough peer review

- Inclusion in PubMed and all major indexing services

- Maximum visibility for your research

Submit your manuscript at www.biomedcentral.com/submit 